\title{
Trends in smoking among adults and smoking- attributable burden in Lithuania
}

\author{
Vaida Liutkutè-Gumarov \\ Health Research Institute, Faculty of Public Health, Medical Academy, Lithuanian University of Health, Kaunas, Lithuania
}

ADDRESS FOR CORRESPONDENCE: Vaida Liutkutè-Gumarov, Health Research Institute, Lithuanian University of Health, Kaunas, Lithuania; e-mail: vaida.liutkute.-.gumarov@lsmu.lt Tilžès g. 18, LT-47181 Kaunas, Lithuania

Supplementary materials (slides from the conference) are available in Webbappendix at the Journal's website: https://www.termedia.pl/ Journal/Journal_of_Health_Inequalities-100

Based on the Health Interview Survey, in 2019, 76\% of population did not smoke, $19 \%$ - smoked every day, $5 \%$ - sometimes. The prevalence of daily smoking decreased from $25 \%$ in 2005 to $19 \%$ in 2019. Compared to 2014 , the proportion of population smoking daily decreased from 20 to $19 \%$. The prevalence of daily smoking in men decreased from $42 \%$ in 2005 to $30 \%$ in 2019 and remained stable in women (10\% in 2005 and $10 \%$ in 2019). In 2019, electronic cigarettes were used daily or occasionally by $12 \%$ of persons aged $15-24$ and by $0.8 \%$ of persons aged 55 and older. Smoking prevalence remains higher among men than women.

Illicit cigarette trade poses a serious threat to public health because it undermines tobacco control policies and allows tobacco industry to engage with policy makers. Methodologically transparent independent cross-sectional survey and collection of discarded cigarette packs was carried out in Lithuania in 2019-2020. National cross-sectional survey determined that illicit share of the total consumption of cigarettes per year was $10.7 \%$. Meanwhile, the empty pack survey revealed a notably higher share: $31.5 \%$ of discarded packs were not intended for the domestic market, with more than $80 \%$ of non-domestic packs originating from Belarus.

Lithuania has a country-specific methodology to asses smoking-attributable harm that is based on the recommendations and guidelines prepared by the WHO and international experts. The last comprehensive assessment of the smoking-attributable harm was performed for the 2003-2013. Analysis at that time showed that smoking remains an important cause of death in Lithuania, carrying over 6 thousand deaths a year. In 2003-2013 smoking accounted for $14.8 \%$ of all deaths and caused one out of 4 deaths in men, and one out of 30 deaths in women. The highest proportion of deaths due to smoking were deaths from cardiovascular diseases, mainly due to smoking caused ischemic heart disease. Most active and passive smoking-attributable deaths occurred in oldest analyzed age groups. In 2003-2013 smoking attributable mortality declined.

On average, outpatient and inpatient healthcare services due to smoking related diseases were provided to 71 thousand people each year (one out of 20 males and one out of 54 women), which accounted for about $3 \%$ of all morbidity cases in Lithuania in 2003-2013. Men most often contacted health care facilities due to smoking-attributable ischemic heart disease, meanwhile women - due to pneumonia, influenza.

Smoking causes high socio-economic harm, which, according to conservative estimates, amounted to nearly $€ 953$ million in Lithuania in 2013, representing 2.7\% of GDP. Estimated costs averaged to $€ 322$ per capita or $€ 1,534$ per smoker. Overall, smoking-attributable costs represented $3.5 \%$ of total healthcare expenditures, meanwhile social security system costs (including sickness benefits and disability and work capacity pensions) represented around $1 \%$ of the total budget of the Compulsory Health Insurance Fund.

The socio-economic harm caused by smoking in Lithuania could be avoided by curbing the consumption of tobacco. Therefore, despite significant progress in tobacco control, implementation of evidence-based tobacco control policies should be further strengthened.

Key words: smoking, smoking-attributable burden, Lithuania.

\section{DISCLOSURE}

The author reports no conflict of interest. 